\title{
Physician Involvement in Promoting Gun Safety
}

\author{
Nicholas Darshan Tolat, MD, JD \\ Bindi Jayendra Naik-Matburia, \\ $M D, M P H^{1,2}$
}

Amy Lynn McGuire, JD, $P b D^{1}$

'Baylor College of Medicine, Houston, Texas

${ }^{2}$ Division of Pediatric Surgery, Texas Children's Hospital, Houston, Texas

\begin{abstract}
Firearm-related deaths are on the rise in the United States, especially among our youth. Tragically, proper firearm storage and safety could have prevented a great number of these deaths. Professional and public health organizations have thus encouraged physicians to provide direct patient counseling on firearm safety. Yet, even with these recommendations, the majority of physicians are still not talking to their patients about this issue. There may be many reasons for this, including concerns about liability, feeling unprepared, patient discomfort, and lack of time during office visits. Despite these concerns, we argue that physicians have an ethical obligation to discuss firearm safety with their patients. Making these discussions a part of routine clinical care would go a long way in the bipartisan effort to protect public safety and improve public health.
\end{abstract}

Ann Fam Med 2020;18:262-264. https://doi.org/10.1370/afm.2516.

$\mathrm{T}$ he number of people who die each year in the United States from firearm-related injuries is on the rise, with more than 38,000 deaths in 2016 alone. ${ }^{1}$ This burden is disproportionately borne by some of the most vulnerable members of society, including our youth. A recent study based on data from the Centers for Disease Control and Prevention (CDC) reports that deaths from gun injuries are now the second leading cause of death in children, almost as common as motor vehicle crashes. ${ }^{2}$ Moreover, unintentional deaths occur most commonly in children who find unsecured guns in their homes and shoot themselves or others. Between 2014 and 2016, 152 children under the age of 12 either killed themselves or were mistakenly shot and killed by another child. ${ }^{3}$ Approximately 1.7 million children (40\%) live in homes with unsafe gun practices, ${ }^{4}$ and 51 children and adolescents in the United States are injured each day due to firearms. ${ }^{5}$ Adults and older individuals are also at risk when guns are improperly stored. From 2006-2016, 6,885 people of all ages in the United States died from unintentional shootings and many more were injured ${ }^{6}$ Tragically, proper gun storage and safety could have prevented a large majority of these deaths and injuries.

In September 2019, 7 leading physician and public health organizations published a joint "call to action" to address this growing public health crisis. ${ }^{7}$ Together, they propose 8 policy recommendations to reduce firearm-related injury and death in the United States. These organizations argue that the medical profession has an obligation to advocate for change in order to reduce gun-related injury and death. They suggest that physicians can and should address this issue directly by counseling their patients about firearm safety. The American Academy of Pediatrics (AAP) similarly recommends that pediatricians routinely inquire about the presence of household firearms and remind parents about the importance of gun safety. ${ }^{8}$ The Asking Saves Kids (ASK) campaign, a collaboration between the Brady Center to Prevent Gun Violence and the AAP, promotes a similar message to both physicians and families to ensure guns are stored properly. ${ }^{9}$ Although many physicians agree that counseling patients on firearm safety is important, a recent study found that only $25 \%$ of physicians surveyed had conversations with patients about firearms or firearm safety often or very often, ${ }^{10}$ which is consistent with findings from studies dating back 20 years. ${ }^{11,12}$

\section{CORRESPONDING AUTHOR}

Amy Lynn McGuire Baylor College of Medicine 1 Baylor Plaza, Suite 310D

Houston, Texas 77030-3411 amcguire@bcm.edu 
It is not clear why physicians are not talking to their patients about gun safety, but we speculate that 4 main challenges contribute. First, physicians may be concerned about potential liability. ${ }^{14}$ In 2011, the Florida legislature passed a law that prohibited physicians from inquiring about a patient's firearm ownership. ${ }^{13}$ This law was in effect for 6 years, until the $11^{\text {th }}$ Circuit Court of Appeals overturned it in 2017 and ruled that it violated physicians' First Amendment right of free speech. ${ }^{14}$ Similar laws have been considered by other state legislatures, but none have come to fruition. ${ }^{14}$ Nevertheless, the push to gag physician speech on firearms may itself influence physicians' willingness to discuss gun safety with their patients.

Second, physicians may feel ill-prepared or uncomfortable discussing firearm safety with their patients. Most physicians do not personally own firearms and very few receive adequate training to have an in-depth conversation with their patients. ${ }^{15}$ A study published in 2007 found that among 922 pediatricians, only about $33 \%$ felt they had adequate training in firearm safety and only $23 \%$ were confident in managing patients with gun injuries. ${ }^{16}$ Since 2007 , there has been an increase in written resources and pamphlets available to help physicians begin such a discussion with patients. The American Foundation for Firearm Injury Reduction in Medicine (AFFIRM) research group has provided a convenient website for clinicians that provides webinars and pamphlets that may be handed out to patients. ${ }^{17}$ Small studies indicate that counseling, even giving written resources, can markedly increase proper storage of firearms. ${ }^{18,19}$ As a result, these new resources can continue to fill the knowledge gap so that physicians feel more equipped to counsel their patients. In addition, adding gun safety counseling to the curriculum for medical students and primary care providers may mitigate this problem for future generations of physicians.

Next, physicians may be worried that patients are reluctant to talk about firearm safety. A 2016 survey of 3,914 US adults found that $46 \%$ of gun owners, $33 \%$ of nonowners living with an owner, and $30 \%$ of nonowners not living with an owner feel that it is never appropriate for physicians to discuss firearms with their patients. ${ }^{20}$ Although we do not know why there is such reluctance to talk about firearms with physicians, one could speculate that patients may not readily see the connection between firearm ownership and risks at home, may feel that physicians do not have the requisite knowledge to provide accurate guidance, or may feel that their physician would be critical of their gun ownership and want to avoid subsequent scorn. The physician-patient relationship is one that is based on trust and breaking this trust could jeopardize the patient's willingness to return for future care. This is a legitimate concern; however, physicians often ask questions that patients may be reluctant or uncomfortable answering. This includes questions about a patient's sexual activity, contraception, smoking habits, and illicit drug use. Physicians also routinely educate patients about issues related to public safety, such as the importance of wearing helmets and using seatbelts. As long as these conversations are respectful and nonjudgmental, they can help build trust and encourage continued dia$\log$ and disclosure rather than destroy it. It is important that all patients are asked these questions to ensure that the individual patient does not feel targeted, and physicians should clarify that they are not there to talk about the issue of gun ownership, only to address the patient's health and safety. Adopting a nonjudgmental, openminded, and culturally sensitive approach is critical when initiating this conversation; indeed, patients have been shown to be much more receptive to the conversation when such an approach is used. ${ }^{21}$

Finally, physicians have routinely indicated that they do not have sufficient time during a clinic visit to discuss firearm safety. In the above 2007 study, only $27.5 \%$ of physicians reported having sufficient time in supervision visits to deal with firearm safety. Indeed, there is a myriad of issues that need to be addressed during a short clinic visit, but there are efficient ways to bring up such a discussion. This includes general questions during an intake form or asking a simple question during the review of the patient's home situation. Questions should focus on the patient's health, be non-accusatory, and open ended. This means not asking blankly, "Do you have a gun?" but instead stating, "Some of my patients have guns at home, and many choose to make them less accessible due to children (or other reasons). Would this be something you would want to talk about today?"22 If time remains an issue, the Massachusetts Medical Society along with the American Academy of Pediatrics have provided clinicians with printable educational materials that can be posted in clinics or handed out to patients about safe firearm storage and disposal. ${ }^{23}$ This could prompt further discussion during the initial visit or subsequent visits and create a dialog between physicians and their patients.

It is important to address these challenges because counseling patients about firearm safety could save lives. In a randomized, controlled, cluster-design study by the Pediatric Research in Office Settings network, an intervention group that received gun-safety counseling from their doctors reported significantly higher rates of handgun removal or safe storage when compared with a control group that received no such counseling. ${ }^{19}$ Another study indicated that even brief counseling efforts by family physicians through a ver- 
bal or written recommendation, such as a brochure, resulted in a significant positive impact on patient firearm storage. ${ }^{20}$ In light of these data, we believe that physicians have an ethical obligation to discuss firearm safety with their patients. As described in the Hippocratic Oath, physicians have a duty to use their expert knowledge and skills to act primarily for the benefit of their patients. ${ }^{24}$ This would include providing accurate and nonjudgmental information regarding gun storage and safety, as well as discussing the grave consequences that could occur in its absence.

Gun violence is an issue that will not go away until change happens. Physicians can and must play a role in this debate moving forward, but many have been frustrated by the politics and have therefore steered clear of advocating for policy reform. A more grassroots effort to effect change involves routinely addressing the issue of gun safety and violence with patients, but many physicians are reluctant to do so because of concerns about liability, discomfort, feeling unprepared, and lack of time. Addressing these concerns so that discussions about gun safety and violence become part of routine clinical care is an important step in the bipartisan effort to protect public safety and improve public health.

To read or post commentaries in response to this article, see it online at http://www.AnnFamMed.org/content/18/3/262.

Key words: firearms; ethics; counseling; physicians

Submitted July 8, 2019; submitted, revised, November 12, 2019; accepted November 21, 2019.

\section{References}

1. Xu J, Murphy SL, Kochanek KD, Bastian B, Arias E. National Vital Statistics Report: Deaths: final data for 2016. https://www.cdc.gov/ nchs/data/nvsr/nvsr67/nvsr67_05.pdf. Published Jul 26, 2018.

2. Cunningham RM, Walton MA, Carter PM. The major causes of death in children and adolescents in the United States. N Engl J Med. 2018;379(25):2468-2475.

3. Penzenstadler N, Foley RJ, Fenn L. A gunshot and a child dies: should anyone be punished? The Denver Post. https://www. denverpost.com/2017/05/24/child-gun-accidental-deaths/. Published May 24, 2017. Accessed Mar 11, 2019.

4. National Partnership for Women $\&$ Families. Politics in the exam room: a growing threat. http://www.nationalpartnership.org/ourwork/resources/repro/politics-in-the-exam-room-a-growing-threat. pdf. Published Oct 2015. Accessed Feb 11, 2019.

5. Everytown for Gun Safety. A nation of survivors: the toll of gun violence in America. https://everytownresearch.org/reports/nationofsurvivors/. Published Feb 1, 2019. Accessed Mar 11, 2019.

6. Aftermath. Examining accidental shooting death statistics. https:// www.aftermath.com/content/accidental-shooting-deaths-statistics/. Accessed Feb 11, 2019.
7. McLean RM, Harris P, Cullen J, et al. Firearm-Related injury and death in the United States: a call to action from the nation's leading physician and public health professional organizations. Ann Intern Med. 2019;171:573-577.

8. Dowd MD, Sege RD; Council on Injury, Violence, and Poison Prevention Executive Committee; American Academy of Pediatrics. Firearm-Related injuries affecting the pediatric population. Pediatrics. 2012;130(5):e1416-e1423.

9. Anderson CW. Are you talking to parents about keeping guns away from children? 5 reasons you absolutely should. Psychology Benefits Society. https://psychologybenefits.org/2017/06/20/ask-daykeeping-guns-away-from-children/. Published Jun 20, 2017.

10. Damari ND, Ahluwalia KS, Viera AJ, Goldstein AO. Continuing medical education and firearm violence counseling. AMA J Ethics. 2018; 20(1):56-68.

11. Butkus R, Weissman A. Internists' attitudes toward prevention of firearm injury. Ann Intern Med. 2014;160(12):821-827.

12. Grossman DC, Mang K, Rivara FP. Firearm injury prevention counseling by pediatricians and family physicians. Practices and beliefs. Arch Pediatr Adolesc Med. 1995;149(9):973-977.

13. Hiltzik M. An appeals court overturns Florida's gag law preventing doctors from asking about guns in the home. Los Angeles Times. https://www.latimes.com/business/hiltzik/la-fi-hiltzik-florida-guns20170217-story.html. Published Feb 17, 2017. Accessed Feb11, 2019.

14. Stern MJ. Docs vs. glocks shows the threat to free speech is the pro-gun right. Slate Magazine. https://slate.com/news-andpolitics/2017/02/the-11th-circuit-strikes-down-floridas-docs-vsglocks-law.html. Published Feb 23, 2017. Accessed Feb 11, 2019.

15. Betz ME, Wintemute GJ. Physician Counseling on firearm safety: a new kind of cultural competence. JAMA. 2015;314(5):449-450.

16. Olson LM, Christoffel KK, O'Connor KG. Pediatricians' involvement in gun injury prevention. Inj Prev. 2007;13(2):99-104.

17. AFFIRM Research. Organizational resources for healthcare professionals. AFFIRM Research. https://affirmresearch.org/2019/04/05/ organizational-resources-for-healthcare-professionals/. Published Oct 10, 2019. Accessed Oct 21, 2019.

18. Barkin SL, Finch SA, Ip EH, et al. Is office-based counseling about media use, timeouts, and firearm storage effective? Results from a cluster-randomized, controlled trial. Pediatrics. 2008;122(1):e15-e25.

19. Albright TL, Burge SK. Improving firearm storage habits: impact of brief office counseling by family physicians. J Am Board Fam Pract. 2003;16(1):40-46.

20. Betz ME, Azrael D, Barber C, et al. Public opinion regarding whether speaking with patients about firearms is appropriate: results of a national survey. Ann Intern Med. 2016;165:543-550.

21. Roszko PJ, Ameli J, Carter PM, Cunningham RM, Ranney ML. Clinician attitudes, screening practices, and interventions to reduce firearm-related injury. Epidemiol Rev. 2016;38(1):87-110.

22. Firearm Violence Resources. Massachusetts Medical Society: Firearm Violence Resources. http://www.massmed.org/Patient-Care/ Health-Topics/Firearm-Violence-Resources/\#.XcgejJJKjjC. Accessed Nov 10, 2019.

23. Gun safety and children. AAP.org. https://www.aap.org/en-us/ about-the-aap/aap-press-room/campaigns/gun-safety. Accessed Nov $10,2019$.

24. Chervenak FA, McCullough LB. The moral foundation of medical leadership: the professional virtues of the physician as fiduciary of the patient. Am J Obstet Gynecol. 2001;184(5):875-879, discussion 879-880. 